\title{
Neglected diseases brought in from the cold
}

Alison Abbott, Munich

The European Commission is launching an ambitious programme to study a group of rare, mostly untreatable, genetic diseases that have so far attracted little attention from research agencies.

The programme, called EUmitocombat, will study diseases caused by defects in the thousand or so genes that regulate the function of mitochondria. These subcellular structures provide the body's cells with energy by breaking down sugars and fatty acids.

Malfunction of a mitochondrial gene occurs in around one in 10,000 births. About half of these lead to a syndrome known as Leigh's disease, in which muscle weakness and brain degeneration usually result in death within five years.

The aim of the programme, which will support a consortium of 21 research groups from nine European countries, is to develop treatment strategies for these inborn disorders. But it could also have spin-offs for more common diseases such as cancer and Parkinson's disease, in which mitochondria may also be implicated.

Jan Smeitink, a consortium leader who runs a centre for mitochondrial disorders at the University of Nijmegen in the

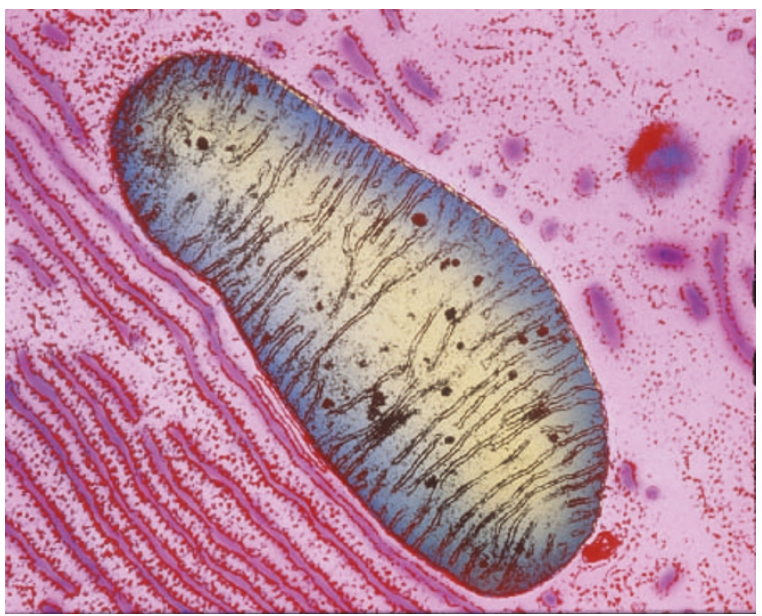

Power failure: defects in the genes that regulate mitochondria, the cell's energy generators, can result in fatal diseases.

Netherlands, says the backing is "the only way that progress can be made".

The number of patients in each category of mitochondrial disease is too small to excite much interest from pharmaceutical companies. And existing sources of public funds often require researchers to pursue short-term goals, which Smeitink says "is not the way to work".

Researchers in the new programme will be expected to work closely with patients. And despite the relative rareness of the conditions, these are not in short supply: "Our centre investigates 300-500 patients a year from the Netherlands and Germany," says Smeitink. He adds that the programme will help to organize all the basic research being carried out on the disease in various laboratories around Europe.

This basic research involves studying mitochondrial genes, including those encoding proteins of the main mitochondrial energy circuit known as oxidative phosphorylation, or oxphos. This circuit produces adenosine triphosphate (ATP), the chemical energy currency of the cell. "We'll be looking systematically for defects and their cell-biological consequences," says Smeitink.

The programme also aims to develop diagnostic tools, and to use improved information on the basic biology of mitochondrial disorders to design treatment strategies - including gene therapy.

At present, only one type of mitochondrial disorder can be treated. It is caused by a very rare defect in the synthesis of an oxphos protein called coenzyme Q. Symptoms can be ameliorated, and deterioration delayed, by oral administration of this protein. But in most disorders, simple replacement of the damaged component does not work.

\section{National park's sale of creationist book draws geologists' ire}

Rex Dalton, San Diego

A slim volume of creationist views on how the Grand Canyon formed has sparked a legal review of books on sale in US national parks.

Lawyers for the National Park Service (NPS) began the review late last year after leading scientists objected to the sale of the creationist book, Grand Canyon: A Different View, in the bookstore at the Grand Canyon National Park in Arizona.

The review is intended to help the NPS to develop a policy for the sale of such material. "The book has raised issues much broader than this book and the canyon," explains David Barna, a spokesman for the NPS.

The beautifully photographed book was compiled by Tom Vail, a river guide with no scientific training. It features a collection of essays by 23 creationists who argue that the towering canyon walls are a record of the six days of creation which, they say, took place about 6,000 years ago. Most geologists say that the Colorado River cut out the canyon between 4 million and 6 million years ago, exposing 1.8 billion years' worth of geological formations.

Wilfred Elders, a geologist at the University of California, Riverside, who first complained about the book's sale at the park, called the volume a collection of "absurdities" that scientifically is "an extraordinary failure".

Complaints from Elders and others caused seven leading Earth-science organizations to write to the NPS on 16 December asking for the book to be removed from the shop - or at least for it to be separated from legitimate scientific texts with which it had been placed last August.

"The book is not about geology, but rather advances a narrow religious view," says the letter signed by presidents of the organizations, which included the Geological Society of America and the American Geophysical Union.

The 104-page book has subsequently

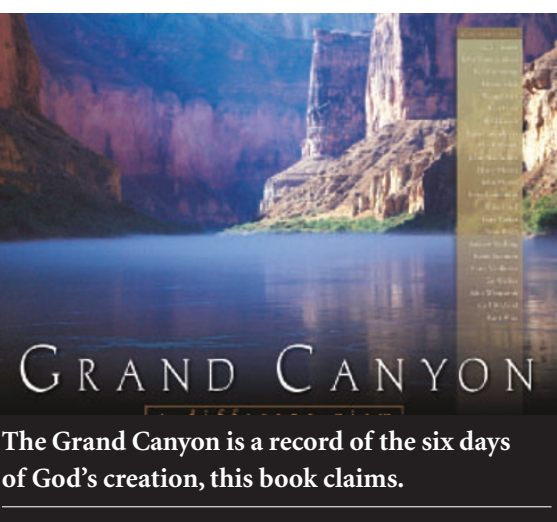

been moved from the science section, but remains on sale in the bookstore. Nearly 300 copies have been sold, according to the bookstore.

Vail says that an alternative to evolutionary science should be offered to members of the public visiting the canyon. "Who is to say whose material should be or shouldn't be in the bookstore?" he asks. That's the tricky question that the NPS review will seek to answer, as it weighs issues such as the display of sound science, the right to free speech and the avoidance of censorship charges. 